\title{
A quantitative study on the effectiveness of a flexible sewerage system for disaster prevention environment issues
}

\author{
H. Shirayanagi ${ }^{1} \&$ Y. Kitamura ${ }^{2}$ \\ ${ }^{I}$ Nara Prefectural Government, Japan \\ ${ }^{2}$ Department of Civil and Environmental Engineering, \\ Faculty of Science and Engineering, Setsunan University, Japan
}

\begin{abstract}
Although the infrastructure in Japan was expanded in the late $20^{\text {th }}$ century to address projected needs, the amount of sewage from homes and factories is rapidly decreasing, creating a sewer system that is not operating near full capacity. Simultaneously, global climate change has increased the risk of a natural disaster (e.g., local flooding), and the capacity of the rainwater drainage system is chronically insufficient. Our research indicates that underground space is not being utilized efficiently. However, the aging population and decline in economic activities have significantly reduced the available capital to maintain and upgrade the existing infrastructure. Because creative solutions are necessary to minimize infrastructure costs, we propose constructing a flexible sewer system. Specifically, we suggest a strategy where rainwater is directed into sewage treatment facilities. Herein we quantitatively show the effects of flexible management of the sewer system using a target district in the Kansai region in Japan. We estimate that the capacity of the rainwater drainage system could be improved from $61.6 \mathrm{~mm} / \mathrm{hr}$ to $65.2 \mathrm{~mm} / \mathrm{hr}$, reducing the likelihood of flood damage in this district by $21.7 \%$.

Keywords: infrastructure, environment, disaster prevention, space reallocation, flexible sewer systems, Intelligent Rainwater and Sewage Systems, IRSS.
\end{abstract}

\section{Introduction}

Due to the massive population increase and industrialization in the late $20^{\text {th }}$ century, Japan built up its infrastructure. Today, however, the amount of sewage 
from homes and factories is rapidly decreasing, and the capital for infrastructure maintenance and renewal has dramatically declined due to the recent low birth rate, aging population, and Japanese companies moving overseas [1]. However, citizens still demand reliable sewer and rainwater drainage systems that meet or exceed the current level of service. These conditions have results in a sewer system that is expensive and not operating near its full capacity. Simultaneously, global climate change has increased the risk of a natural disaster, such as local flooding due to torrential rain. Unfortunately the capacity of the rainwater drainage system in Japan is insufficient. Thus, creative solutions are necessary to minimize the cost of infrastructure renewal and maintenance $[2,3]$.

Our research indicates that urban sewer systems do not efficiently utilize underground space with respect to environmental issues and disaster prevention. Thus, we suggest the strategic implementation of a flexible sewer system that can handle both sewage and rainwater drainage. Herein we develop a scheme where rainwater, which is polluted or exceeds the capacity of the rainwater drainage system, is directed into sewage treatment facilities, and quantitatively show the impact of a flexible sewer system on environmental issues and disaster prevention.

The rest of this paper is organized as follows. Section 2 comments on the current conditions and problems of the sewer and rainwater drainage systems in the target area. We suggest reallocation is necessary to improve the spatial conditions. Section 3 proposes a framework for a flexible sewer system, and shows the effects with respect to environmental issues and disaster prevention. Section 4 uses hydrograph analysis to evaluate the implementation of a flexible sewer system, while Section 5 quantitatively assesses the effectiveness of a flexible sewer system. Finally Section 6 summarizes the research results, addresses implementation hurdles, and provides suggestions to improve the sewer and rainwater drainage systems.

\section{Conditions and problems}

\subsection{Sewer system}

In our study, the target area is Nagaokakyo city, which is located on flat protected lowland in the Kansai region of Japan. The population density for inhabitable land is about 7,000 persons $/ \mathrm{km}^{2}$.

Nagaokakyo city began treating sewage in 1974 . The diffusion rate of the sewer systems is $99.3 \%$ (April 1, 2013). Although the city's population now is comparable to that in 1974, the amount of drainage from homes and factories has drastically decreased due to a decline in economic activities and improvements in polluted water processing techniques. Consequently, the sewer system (both sewage pipes and disposal plants) is not operating near its designed capacity in the target area. 


\subsection{Rainwater drainage system}

In the target area, the probable maximum precipitation is $53.1 \mathrm{~mm} / \mathrm{hr}$ (return period: 5 years) and $61.6 \mathrm{~mm} / \mathrm{hr}$ (return period: 10 years). However, precipitation of $76.5 \mathrm{~mm} / \mathrm{hr}$ (July 2008) and $96.0 \mathrm{~mm} / \mathrm{hr}$ (August 2010) were reported. Thus, heavy rainfall can lead to flooding and damage in the target area. Additionally, global climate change has increased the risk of a natural disaster (e.g., local flooding due to torrential rain). However, the capacity of the rainwater drainage system remains insufficient due to the slow outflow from the flat protected lowland and difficulties improving the rainwater drainage system.

\subsection{Spatial conditions of rainwater drainage and sewer systems}

The previous two sections demonstrate that underground space is inefficiently utilized in urban sewer systems. Figure 1 shows the current utilization of underground space for sewage and drainage. Reallocation of this space could greatly improve the spatial conditions of the rainwater drainage and sewer systems.

\section{Local flooding by heavy rain}

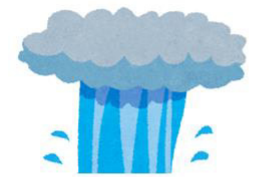

The capacity of rainwater drainage system remains chronically short

The capacity of sewage system is overcapacity

homes factories

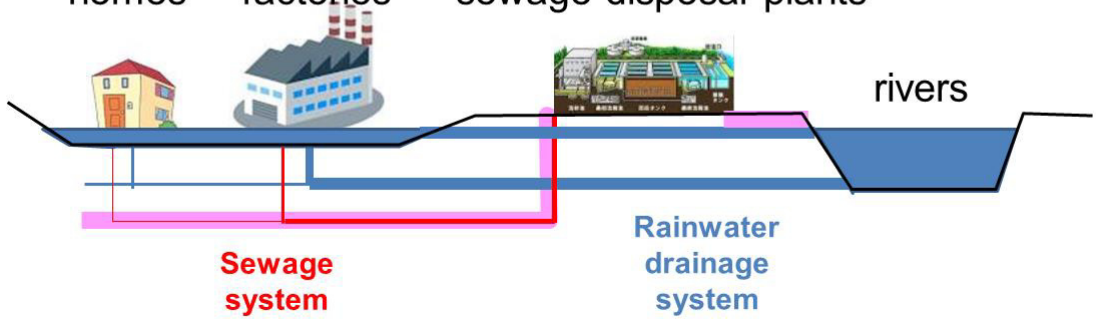

Figure 1: Spatial conditions of the rainwater drainage and sewer systems.

\section{Flexible sewer system}

\subsection{Framework of a flexible sewer system}

Figure 2 depicts the framework for a flexible sewer system that can accommodate both sewage and rainwater drainage. As a disaster prevention measure, when heavy rain or another critical situation causes the rainwater drainage system to reach capacity, the spare space in the sewage (polluted water) pipes allows rainwater to flow into sewage treatment facilities. Instead of 
permanently combining the sewer and rainwater drainage systems, a flexible sewer system has the ability to allow the some rainwater to flow into the sewer system when needed.

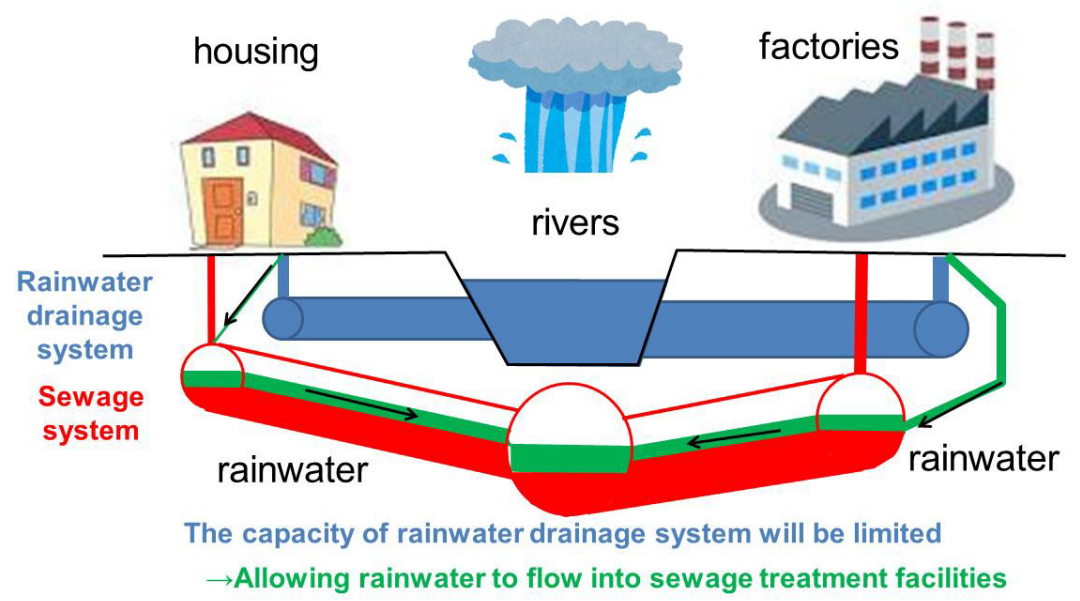

Figure 2: Framework for a flexible sewer system.

\subsection{Effects of a flexible sewer system}

\subsubsection{Decreased damage from local flooding}

Figure 3 shows the impact of increasing the capacity of the rainwater drainage system. Using the currently unused space of the sewer system allows rainwater to flow to sewage treatment facilities, thereby increasing the capacity of the rainwater drainage system while reducing the frequency of local flooding.

Figure 4 shows the effect of reducing damage due to local flooding. Prior to implementing a flexible sewer system, each district has its own rainwater drainage system or systems. However, the flexible sewer system allows multiple

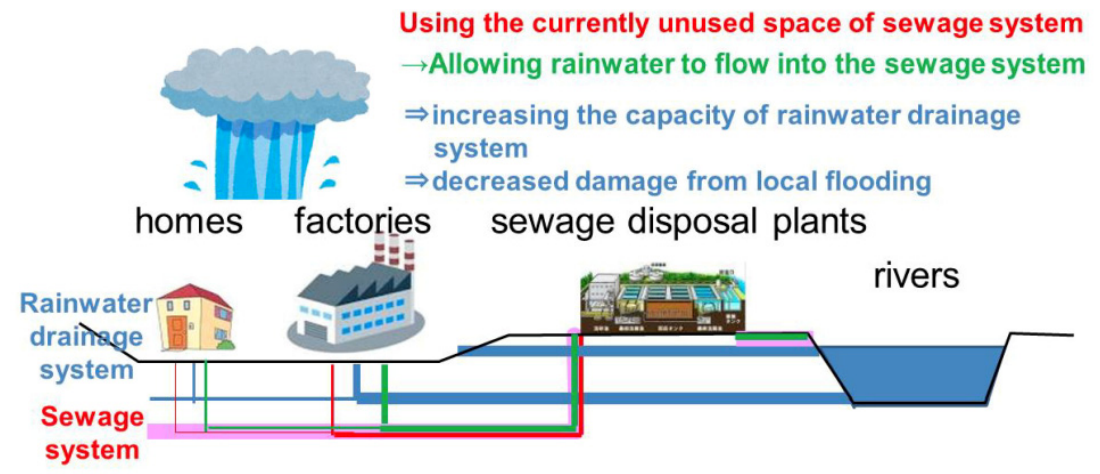

Figure 3: Impact of increasing the capacity of the rainwater drainage system. 


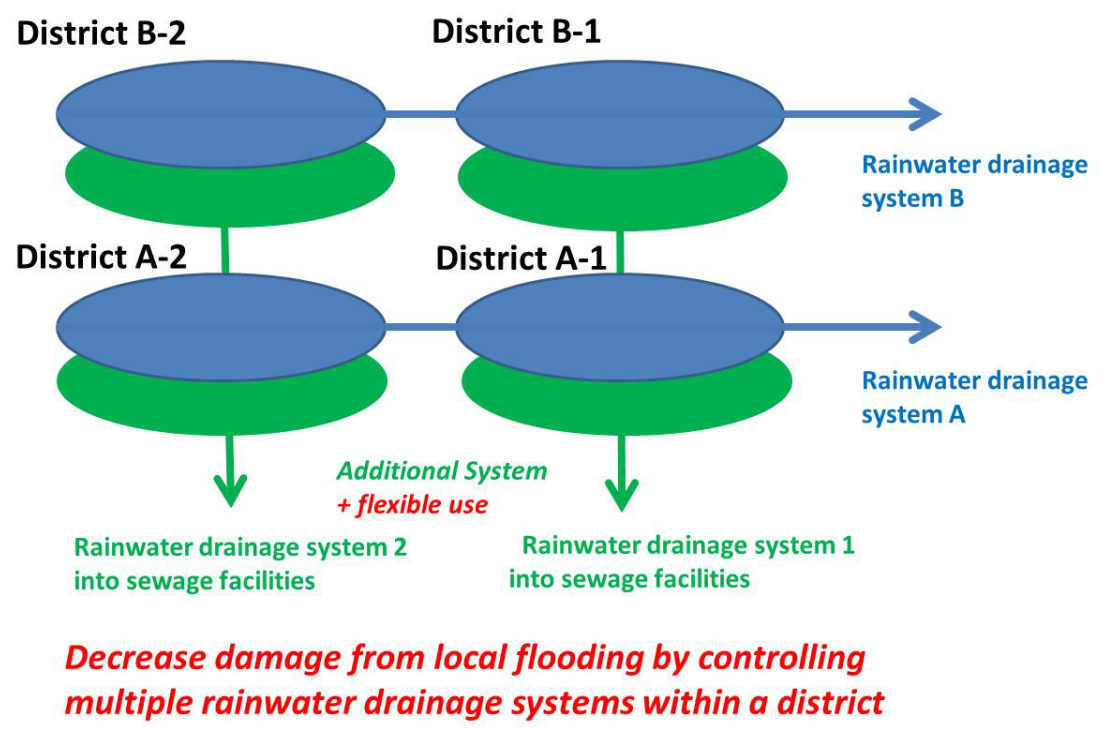

Figure 4: Impact of a flexible sewer system on damage from local flooding.

rainwater drainage systems within a district and from different districts to function as one larger unit, which will decrease damage from local flooding.

\subsubsection{Impact on environmental issues}

Figure 5 shows the effect of a flexible sewer system on environmental issues. The initial rainwater is polluted water from multiple sources, including dust on the road. By allowing the initial rainwater to flow to sewage treatment facilities, less polluted water will be discharged into the river. Additionally, rainwater will rinse out the sewage (polluted water) pipes, which should have a positive environmental impact, such as deodorizing the sewage pipes.

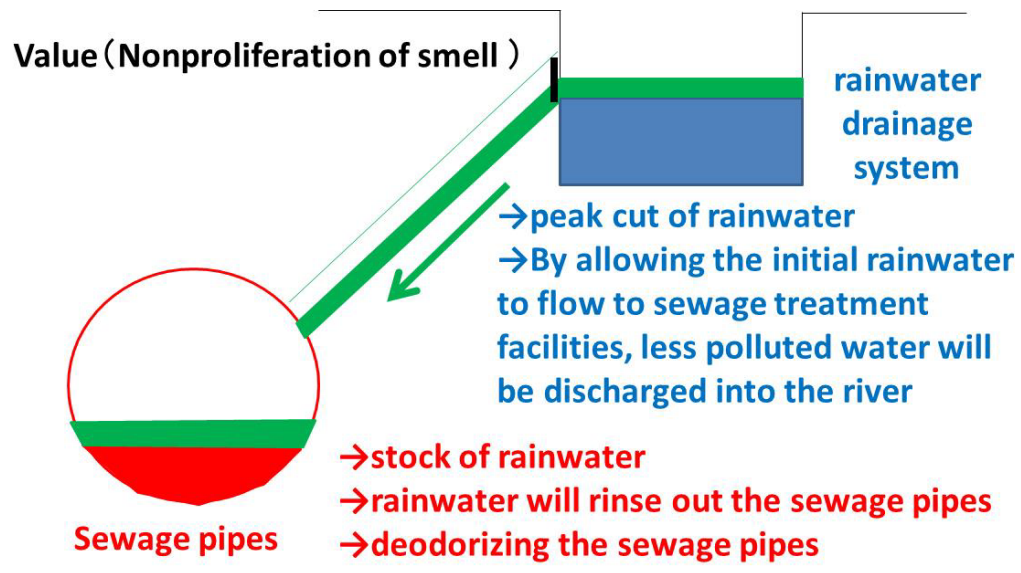

Figure 5: Effects on environmental issues. 


\section{Hydrograph analysis}

\subsection{Modeling}

Figure 6 is a model of hydrograph analysis, which depicts the inflow into the target district $(=\mathrm{A})$, inflow of rain to the target district $(=\mathrm{B})$, outflow from the target district $(=\mathrm{C})$, and capacity of the outflow from the target district $(=\mathrm{Cmax})$.

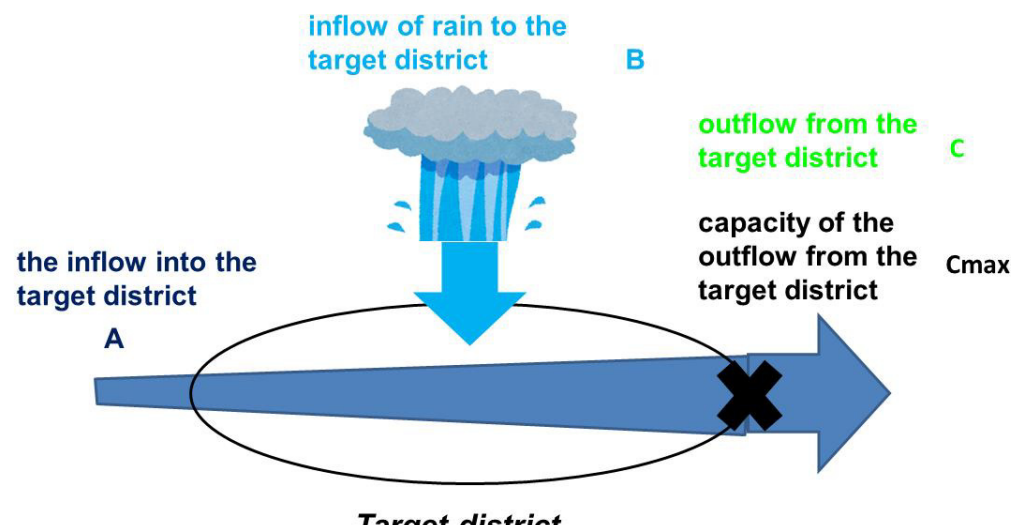

Target district

Figure 6: A model of hydrograph analysis.

\subsection{Before implementing a flexible sewerage system}

Figure 7 shows the time series of $\mathrm{A}, \mathrm{B}$, and $\mathrm{Cmax}$ prior to implementing a flexible sewer system. When $\mathrm{A}+\mathrm{B}$ is less than $\mathrm{Cmax}, \mathrm{C}$ is equal to $\mathrm{A}+\mathrm{B}$. However, when $\mathrm{A}+\mathrm{B}$ exceeds $\mathrm{Cmax}, \mathrm{C}$ is equal to Cmax. Thus, $\mathrm{A}+\mathrm{B}-\mathrm{Cmax}$ is collected in the target district, and a negative value indicates local flooding. Additionally, even if $\mathrm{A}+\mathrm{B}$ is less than Cmax, but the rain persists, $\mathrm{C}$ may become $\mathrm{Cmax}$ for local flooding. When a local flooding is zero, $\mathrm{C}$ is less than $\mathrm{Cmax}$.

\subsection{After implementing a flexible sewerage system}

Figure 8 shows the times series for A, B, and Cmax after implementing a flexible sewer system. The capacity of the outflow from the target district is assumed to be $\mathrm{Cmax}+\mathrm{D}$ where $\mathrm{D}$ is the spare pockets in the sewage (polluted water) pipes. If $\mathrm{A}+\mathrm{B}$ is less than $\mathrm{Cmax}+\mathrm{D}$, then local flooding does not occur. Even if $\mathrm{A}+\mathrm{B}$ exceeds $\mathrm{Cmax}+\mathrm{D}$, the flooding is less severe than prior to implementing a flexible sewer system. 


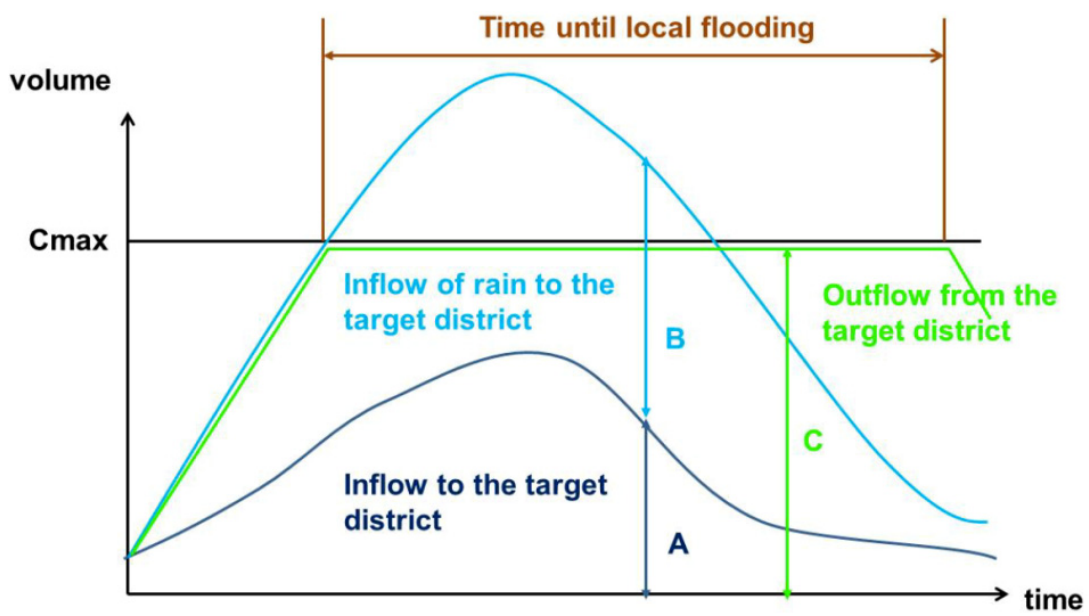

Figure 7: Inflow and outflow volumes before implementing a flexible sewerage system.

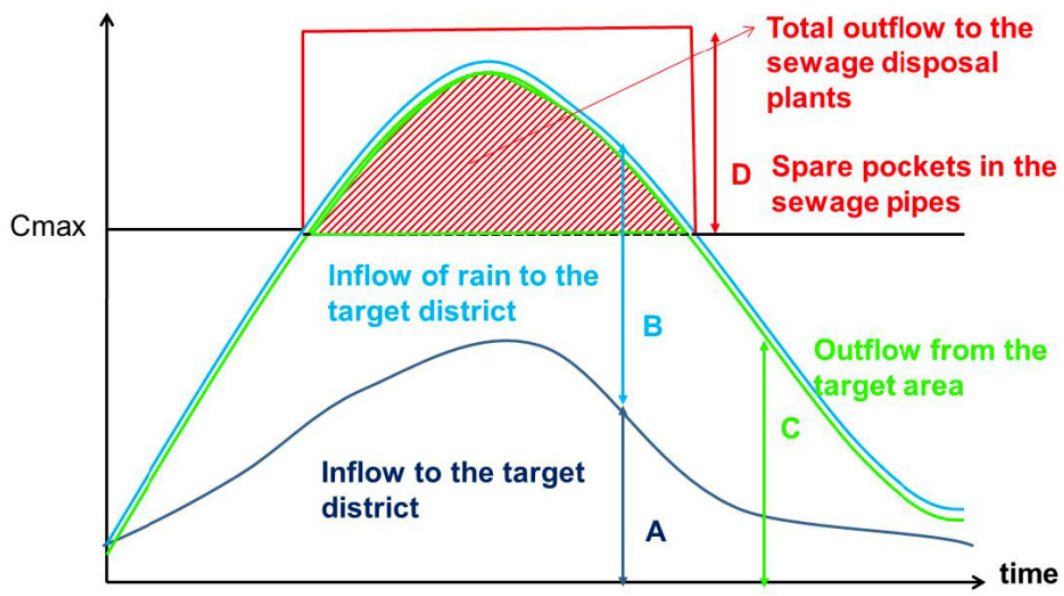

Figure 8: Inflow and outflow volumes in the flexible sewer system.

\section{Evaluation}

\subsection{Increased capacity of the rainwater drainage system}

The target of our study is a district in Nagaokakyo city, which has an area of $0.8 \mathrm{~km}^{2}$ and is often subject to local flooding due to torrential rain. Currently, the capacity of the rainwater drainage system in the target district is rainfall of 
$53.1 \mathrm{~mm} / \mathrm{hr}$. By adding the $6,700 \mathrm{~m}^{3}$ of the spare pockets to the rainwater drainage system, the increased capacity would support rainfall of $61.6 \mathrm{~mm} / \mathrm{hr}$ (Fig. 9). The additional volume from the spare pockets can dispose of the $8.5 \mathrm{~mm} / \mathrm{hr}$ rainfall. Upon considering the inflow and maximum outflow volumes, the spare pockets will be full after $0.618 \mathrm{hr}$ of rainfall at $61.6 \mathrm{~mm} / \mathrm{hr}$.

In our estimation of the increased capacity by implementing a flexible sewer system, we assumed that the spare pockets can handle $50 \%$ of the space of sewage pipes $\left(2,040 \mathrm{~m}^{3}\right)$, and the outflow can handle $50 \%$ of the maximum outflow volume $\left(2,442 \mathrm{~m}^{3} / \mathrm{hr}\right)$. We also assumed that the spare pockets in the sewage treatment facilities will be full after $0.618 \mathrm{hr}$ of rainfall in the target area. Consequently, the spare pockets can dispose of an additional $3.6 \mathrm{~mm} / \mathrm{hr}$ of rainfall in the target area, which increases the capacity from $61.6 \mathrm{~mm} / \mathrm{hr}$ to $65.2 \mathrm{~mm} / \mathrm{hr}$.

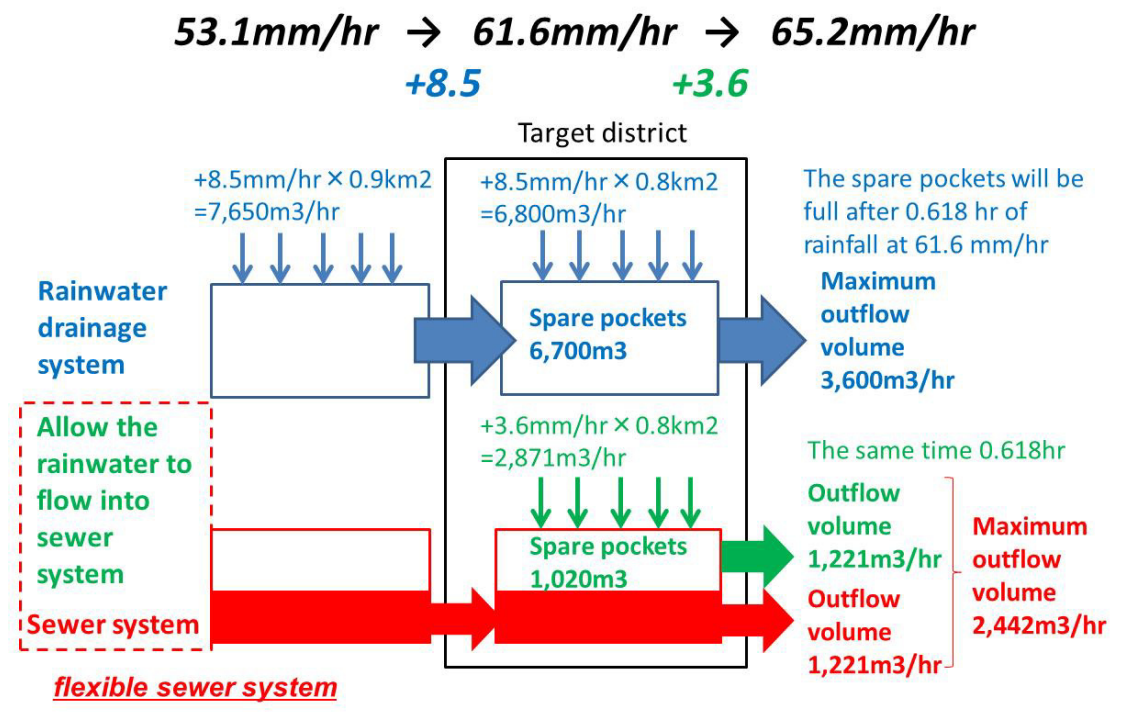

Figure 9: Increase in the capacity of the rainwater drainage system.

\subsection{Reduced likelihood of flood damage}

We estimated the likelihood of flood damage in the target district with a flexible sewer system using an analysis program for rain, AMEDAS (Automatic Meteorological Data Acquisition System) [4]. The Fair-formula used this program can be expressed as equation (1).

$$
\mathrm{r}(\mathrm{T}, \mathrm{t})=\frac{b T^{m}}{(t+a)^{n}}
$$

$\mathrm{r}(\mathrm{T}, \mathrm{t})$ : rainfall intensity $(\mathrm{mm} / \mathrm{hr})$

$\mathrm{T}$ : return period (year/times)

$\mathrm{t}$ : continuous time of rainwater $(\mathrm{hr}) \mathrm{t}=1$

$\mathrm{a}, \mathrm{b}, \mathrm{m}, \mathrm{n}$ : parameters designed by the target district 


$$
(\mathrm{a}=0.13, \mathrm{~b}=38.35196, \mathrm{~m}=0.232421, \mathrm{n}=0.6687551)
$$

The likelihood of flood damage is estimated before and after implementing a flexible sewer system. Prior to a flexible sewer system, flood damage occurs when rainfall exceeds $61.6 \mathrm{~mm} / \mathrm{hr}$ with a frequency of 0.0916 times/year. After implementing a flexible sewer system, flood damage does not occur until rainfall exceeds $65.2 \mathrm{~mm} / \mathrm{hr}$, reducing the frequency to 0.0717 times/year. Consequently, implementing a flexible sewer system would reduce the likelihood of flood damage in this district by $21.7 \%$.

\section{Conclusion}

This study commented on the conditions and problems with Japan's infrastructure, mainly the sewer and rainwater drainage systems. Space allocation is required to improve the spatial conditions and functions. We propose a strategy involving a flexible sewer system as an economically feasible long-term solution, and demonstrate its impact on environmental issues and disaster prevention using a target district in Japan. In addition to fully utilizing the sewer system, which is currently not operating near full capacity, we estimated that the capacity of the rainwater drainage system would improve from $61.6 \mathrm{~mm} / \mathrm{hr}$ to $65.2 \mathrm{~mm} / \mathrm{hr}$ without degrading the current quality of the sewer system. This increased capacity will reduce the likelihood of flood damage in this district by $21.7 \%$.

Although adopting the strategy of a flexible sewer system will resolve many issues, there are some institutional and technical hurdles. Because the sewer system is operated as a business based on city planning decisions, it is important to readjust the various relevant authorities. Another technical problem is how to control the inflow and outflow of rainfall into sewage treatment facilities. That is, the inflow load for sewage must remain at the current reduced levels. To address these problems, we suggest the following two measures. First, the rainwater drainage and sewer systems should be considered as one single entity that is managed by city (and not individual districts). Second, the Intelligent Rainwater and Sewage Systems (IRSS) should be adopted in consideration of environmental issues and disaster prevention. However, the proper management and policies will provide a long-term strategy for disaster prevention and environmental protection, while meeting the needs of the citizens.

\section{References}

[1] Norio Miyasaka \& Yuzou Iwata, A study on Establishing NPM-Type Management Systems for Social Capital Infrastructure, http://www.murc.jp/thinktank/rc/quarterly/quarterly detail/200804 137.pdf

[2] Water Quality Control Department Water System Division, A research on the stock management in sewage pipes, National Institute for Land and Infrastructure Management Ministry of Land, Infrastructure, Transport and Tourism, FY2010 Annual Report of Wastewater Management and Water Quality Control, 2010 
[3] Kiyoyuki Kaito, Toshiro Kameda, Akira Ohtani and Akihiko Yanamaka, Stock Management of Sewerage Concrete Pipes, http://www.pacific.co.jp/thesis/item/jyougesui $05 \mathrm{pdf}$

[4] Global Centre of Excellence for Water Hazard and Risk Management (ICHARM), Analysing program of rain probability by using AMEDAS (Automatic Meteorological Data Acquisition System), http://www.pwri.go.jp/jpn/seika/amedas/top.htm 